\title{
Thermic effect of a meal and appetite in adults: an individual participant data meta-analysis of meal-test trials
}

\author{
Anne-Marie Ravn'*, Nikolaj Ture Gregersen', \\ Robin Christensen², Lone Graasbøl Rasmussen', Ole Hels³, \\ Anita Belza', Anne Raben', Thomas Meinert Larsen', \\ Søren Toubro ${ }^{4}$ and Arne Astrup'
}

'Faculty of Science, Department of Nutrition, Exercise and Sports, University of Copenhagen, Frederiksberg C, Denmark; ${ }^{2}$ The Parker Institute: Musculoskeletal Statistics Unit, Copenhagen University Hospital at Bispebjerg and Frederiksberg, Copenhagen, Denmark; ${ }^{3}$ StatistiConsult, Ølstykke, Denmark; ${ }^{4}$ Reduce APS - Research Clinic of Nutrition, Roskilde, Denmark

\section{Abstract}

Background: Thermic effect of a meal (TEF) has previously been suggested to influence appetite.

Objective: The aim of this study was to assess whether there is an association between appetite and TEF. Second, to examine whether protein intake is associated with TEF or appetite.

Design: Individual participant data (IPD) meta-analysis on studies were performed at the Department of Nutrition, Exercise and Sports, University of Copenhagen, Denmark. Five randomized meal-test studies, with 111 participants, were included. The included studies measured energy expenditure (EE) in respiration chambers and pre- and postprandial appetite sensations using Visual Analog Scales (VAS). The primary metaanalysis was based on a generic-inverse variance random-effects model, pooling individual study Spearman's correlation coefficients, resulting in a combined $r$-value with $95 \%$ confidence interval $(95 \% \mathrm{CI})$. The $I^{2}$ value quantifies the proportion ( $\%$ of the variation in point estimates due to among-study differences.

Results: The IPD meta-analysis found no association between satiety and TEF expressed as the incremental area under the curve $\left(\mathrm{TEF}_{\mathrm{iAUC}}\right)\left(r=0.06[95 \% \mathrm{CI}-0.16\right.$ to 0.28$\left.], P=0.58 ; I^{2}=15.8 \%\right)$. Similarly, Composite Appetite Score (CAS) was not associated with $\mathrm{TEF}_{\mathrm{iAUC}}\left(r=0.08[95 \% \mathrm{CI}-0.12\right.$ to 0.28$], P=0.45 ; I^{2}=0 \%$ ). Posthoc analyses showed no association between satiety or CAS and TEF expressed as a percentage of energy intake $(\mathrm{EI})(P>0.49)$ or TEF expressed as a percentage of baseline $\mathrm{EE}(P>0.17)$. When adjusting for covariates, $\mathrm{TEF}_{\mathrm{iAUC}}$ was associated with protein intake $(P=0.0085)$.

Conclusions: This IPD meta-analysis found no evidence supporting an association between satiety or CAS and TEF at protein intakes $\sim 15 \mathrm{E} \%$ (range $11-30 \mathrm{E} \%$ ).

Keywords: thermic effect of a meal; diet-induced thermogenesis; appetite; energy expenditure; satiety; Composite Appetite Score

To access the appendices to this article please see Supplementary files under Article Tools online

Received: 6 September 2012; Revised: 16 May 2013; Accepted: II November 2013; Published: 23 December 2013

$\mathrm{H}$ uman appetite involves repeated increases and decreases in the desire to eat and is controlled by psychological, physiological, and biochemical mechanisms $(1,2)$. Thermic effect of a meal (TEF) is the increase in energy expenditure (EE) engendered by the energy used in the postprandial period in the process of absorbing, metabolizing, and storing ingested nutrients $(3,4)$.

TEF has previously been suggested as one of the mechanisms that influences appetite sensations, including satiety $(5,6)$. Strominger and Brobeck (5) hypothesized that increased body temperature, caused by both 
environmental temperature and the extra heat released during the digestion of food (i.e. TEF), could result in a reduced food intake. Later, Westerterp-Plantenga et al. (6) suggested that the basis of the association between TEF and satiety might be that the increased EE at rest after food intake causes increased oxygen consumption and body temperature. This could then give rise to the body feeling deprived of oxygen and be translated into a sensation of satiety (6). The same relationship between oxygen deprivation and appetite has previously been observed in mountain climbers at high altitudes, although the causal association has not been thoroughly investigated $(7,8)$. Bearing the above in mind, it is of interest to consider the effect of diet, such as particular macronutrients, on TEF and consequently on appetite regulation.

Studies on appetite and thermogenesis have shown protein to be superior to other macronutrients in promoting satiety $(2,7)$. In addition, protein causes higher TEF $(20-30 \%$ of the energy content of ingested protein) compared to carbohydrate $(5-10 \%)$ and fat $(0-3 \%)$ (9). This is due to the large amount of adenosine triphosphate (ATP) used in the postprandial period in the process of metabolizing and storing protein (9). As protein is the most satiating and thermogenic nutrient, the association between TEF and appetite suggested by Strominger and Brobeck in 1953 could be plausible (5).

Even a small positive association between TEF and satiety could have clinical implications during weight loss. We therefore undertook an individual participant data (IPD) meta-analysis on studies previously conducted at our department, to investigate whether an association between the perception of appetite and TEF exists, and whether protein intake is an influential factor.

\section{Present investigation}

\section{Methods}

Eligibility criteria

Studies conducted at the Department of Nutrition, Exercise and Sports, Faculty of Science, University of Copenhagen, Denmark, from 1992 to 2006 were available for inclusion in this study. Studies were included if they contained: 1) data on at least 24-h EE measurements in whole-body respiration chambers; 2) baseline measurements and a minimum of three measurements of appetite sensations after a dinner meal using visual analog scales (VAS); and 3) detailed descriptions of energy intake (EI). To obtain individual energy balance during the chamber stay, EI provided was based on equations estimating EE. In studies where active components (e.g. medication, enriched foods, etc.) were tested, only the control measurements done without these active components were included in this IPD meta-analysis. If more than one measurement was carried out on the same participant, and if both measurements matched the criteria above, only the last measurement was included. Finally, all included participants had to be healthy, non-smoking, and non-elite athletes (less than $10 \mathrm{~h}$ of exercise a week).

Respiratory measurements

EE was measured by indirect whole-body calorimetry in a $14.7 \mathrm{~m}^{3}$ open-circuit respiration chamber at the Faculty of Science (University of Copenhagen, Denmark). The design of the chambers has been described in detail elsewhere (10). In the included studies, oxygen and carbon dioxide exchange including urinary nitrogen measurements were used to calculate EE. Spontaneous physical activity (SPA) in the respiration chambers was assessed using two microwave radar devices. The within-subject variation for 24-h EE measured in the chambers is $2.3 \%$ and the within-subject variation for 1-h measurements of basal EE is 5\% (10). Resting metabolic rate (RMR) was measured in a resting period of $30 \mathrm{~min}$ just before the dinner meal was served.

Visual analog scales

VAS were used for measuring the subjective appetite sensations of satiety, hunger, fullness, and prospective food intake. The scale consists of a horizontal line (100 $\mathrm{mm}$ in length) with the most positive and most negative sensations at opposite ends of the line. Participants mark the line at a point corresponding to their perceived appetite at a given time. For satiety, the question was 'How satisfied do you feel?', and the text anchors were 'I am completely empty' and 'I cannot eat another bite'. For fullness, hunger and prospective food intake the questions were 'How full do you feel?' (text anchors: 'Not at all full' and 'Totally full'), 'How hungry do you feel?' (text anchors: 'I am not hungry at all' and 'I have never been hungrier') and 'How much do you think you could eat?' (text anchors: 'Nothing at all' and 'A lot'), respectively.

The reproducibility and validity of VAS have previously been examined by Flint et al. (11), who concluded that VAS provide a reliable tool for a quantitative measurement of subjective sensations such as appetite in single meal-test trials. Finally, Composite Appetite Score (CAS) was included in the study. This measure reflects the four VAS questions and was included in the study as a summary measure of appetite. CAS was calculated using the formula inspired by Anderson et al. (12): CAS $=((100-$ satiety $)+$ $(100-$ fullness $)+$ hunger + prospective food intake $) / 4$.

Data

Data were acquired by contacting the principal investigators, searching old records, and contacting the research department where the studies were conducted. The data of all of the included participants were checked for duplicates and were checked twice (by a second reviewer) before being included in the IPD meta-analysis. 
Data were extracted from previously collected data and were treated as confidential.

Data on appetite (VAS scores on satiety and CAS [including satiety, fullness, hunger, and prospective food intake]) just before ingestion of the dinner meal and until 180 min after the meal were extracted from each of the included studies. Similarly, data on EE measurements 30 min before the dinner and until $180 \mathrm{~min}$ postprandially were also extracted. Furthermore, data on sex, age, height, body weight, EI, fat-free mass, fat mass, body fat percentage, and tea/coffee ingested after dinner (yes/ no) were also collected. VAS was calculated as the incremental area under or over the curve (iAUC and iAOC, respectively) using VAS measurements filled out immediately before the dinner as baseline. The examined appetite measures were Satiety $\mathrm{iAUC}_{\mathrm{A}}$ and CAS.

TEF was calculated in three different ways. The primary TEF measure was calculated as the incremental area under the curve for resting EE after the dinner meal with RMR used as the baseline measure $\left(\mathrm{TEF}_{\mathrm{iAUC}}\right)$ and expressed in $k J / 3 \mathrm{~h}$. For the purpose of sensitivity analysis, we also scrutinized other ways to interpret TEF: (1) TEF as the increase in EE above baseline expressed as a percentage of EI in dinner meal $\left(\mathrm{TEF} \%_{\mathrm{EI}}\right)$; and (2) TEF as the increase in EE above baseline expressed as a percentage of baseline (TEF\%) as secondary TEF measures. These TEF measures were included in posthoc analyses of satiety and CAS. We preferred the dinner meal as this normally included $30-40 \%$ of the total EI during the stay.

\section{Quality of included studies}

All included studies were randomized controlled trials with either parallel (13-16) or crossover (17) design. Four of the studies used either a single- $(15,17)$ or doubleblinded design $(13,14)$. Two of the studies were placebocontrolled trials testing potential drug candidates (13, 14). The remaining three studies all tested different diets against each other (15-17).

\section{Statistical analysis}

The raw data included from each study were analyzed separately to acquire summary statistics in the form of Spearman's $r$-coefficient and the corresponding standard error (SE), reflecting the level of statistical significance in the individual tests for association in the different eligible trials. The SE for the non-parametric Spearman's $r$-coefficient (SE[r]) was estimated from the (two-sided) $P$-value converted into a standard normal score $(Z)$, which enabled an estimate of $\mathrm{SE}[r]$ using Wald-test methodology $(Z[r]=r / \mathrm{SE}[r])$. All results are reported with $95 \%$ confidence intervals $(95 \% \mathrm{CI})$, that were calculated as the estimate for coefficient $r \pm 1.96 *$ SE. For the purpose of sensitivity analysis, these Wald-testconverted SEs were re-confirmed when estimated using the approach proposed by Thompson et al. (18) using the Fisher-transformed correlation (and SE) derived from the reported $P$-value and the sample size.

The summary analyses were computed using homogeneity statistics to evaluate the agreement of the individual trial results with a fixed-effect meta-analytic summary (19). However, for the overall inference we used standard random-effects meta-analysis (20) as a default option; the fixed-effect analysis would apply as a sensitivity analysis in the case of inconsistency. We estimated inconsistency by calculating the $I^{2}$ statistic (21), which describes the percentage of total variation across trials that is attributable to heterogeneity rather than to chance (22).

We performed a number of pre-specified sensitivity analyses based on a statistically more advanced hierarchical model. At level one in the hierarchical model, participants were compared with others from the same study (i.e. trial numbers were applied as clusters), enabling the entire dataset to be analyzed as if it originated from a single study (23). A random coefficient model was applied to assess the five different possible linear associations simultaneously (24). Random coefficient models emerge as natural mixed-model extensions of simple linear regression models in a hierarchical (nested) data setup. As we treated each study as a random sample, it was natural to incorporate this in the model by assuming the subject effects (trial intercepts and slopes) to be random (25). These models enabled inclusion of potentially confounding factors included in Table 1; factors and covariates that could influence the overall summary association across included studies (see Supplementary file). These hierarchical models derived from maximum likelihood estimates were performed using the SAS software (version 9.2).

\section{Results}

\section{Inclusion of studies}

A flowchart of the selection and inclusion process is given in Fig. 1. Twenty-eight studies included measurements from respiration chambers as a part of the investigations conducted at Department of Nutrition, Exercise and Sports in the period from 1992 to 2006 and therefore fulfilled these two inclusion criteria. However, 20 of these studies were excluded due to the following factors: less than three VAS measurements after the dinner meal (10, 26-41), ad libitum dinner meal (42), EE measurements shorter than $24 \mathrm{~h}$ (43), or the participants had hyperthyroidism (44). Furthermore, three studies were excluded because it was not possible to locate data (45). Thus, five studies were found eligible for inclusion in the metaanalysis. These five studies (13-17) included a total of 280 participants. In two of the five included studies, measurements in respiration chambers were carried out only on a 
Table 1. Summary of study characteristics of all participants

\begin{tabular}{|c|c|c|c|c|c|c|}
\hline Variable & Raben et al. (15) & Hansen et al. (I3) & Mikkelsen et al. (I7) & Larsen et al. (14) & Rasmussen et al. (16) & Total \\
\hline Publication year & 2002 & 1999 & 2000 & 2002 & 2007 & - \\
\hline$N$ & 19 & 32 & 12 & 10 & 38 & 111 \\
\hline Males, no. (\%) & $3(16 \%)$ & 7 (22\%) & $12(100 \%)$ & $10(100 \%)$ & $16(42 \%)$ & $48(43 \%)$ \\
\hline Age, years & $\begin{array}{l}35.4 \pm 10.7 \\
(20.0 ; 50.0)\end{array}$ & $\begin{array}{l}38.5 \pm 9.05 \\
(20.0 ; 54.0)\end{array}$ & $\begin{array}{l}25.6 \pm 3.2 \\
(21.0 ; 31.0)\end{array}$ & $\begin{array}{l}36.1 \pm 7.6 \\
(25.0 ; 47.0)\end{array}$ & $\begin{array}{l}27.1 \pm 5.2 \\
(18.0 ; 36.0)\end{array}$ & $\begin{array}{l}32.3 \pm 9.4 \\
(18.0 ; 54.0)\end{array}$ \\
\hline Caffeine (yes/no') & Yes & No & No & Yes & No & - \\
\hline SPA $\left(\% / h^{2}\right)$ & $\begin{array}{c}7.4 \pm 3.6 \\
(3.7 ; 19.3)\end{array}$ & $\begin{array}{c}7.9 \pm 3.9 \\
(2.9 ; 21.3)\end{array}$ & $\begin{array}{c}8.0 \pm 1.7 \\
(6.1 ; 11.2)\end{array}$ & $\begin{array}{c}8.3 \pm 2.7 \\
(4.7 ; 12.9)\end{array}$ & $\begin{array}{l}6.3 \pm 2.0 \\
(2.7 ; 10.8)\end{array}$ & $\begin{array}{l}7.3 \pm 3.1 \\
(2.7 ; 21.3)\end{array}$ \\
\hline BMI $\left(\mathrm{kg} / \mathrm{m}^{2}\right)$ & $\begin{array}{l}28.2 \pm 2.4 \\
(24.3 ; 32.6)\end{array}$ & $\begin{array}{l}33.8 \pm 2.7 \\
(30.4 ; 40.0)\end{array}$ & $\begin{array}{l}29.2 \pm 1.8 \\
(26.8 ; 31.9)\end{array}$ & $\begin{array}{l}31.3 \pm 2.1 \\
(28.3 ; 34.3)\end{array}$ & $\begin{array}{l}28.2 \pm 2.4 \\
(22.5 ; 33.4)\end{array}$ & $\begin{array}{l}30.2 \pm 3.4 \\
(22.5 ; 40.0)\end{array}$ \\
\hline El dinner $\left.(\mathrm{M})^{3}\right)$ & $\begin{array}{l}3.38 \pm 0.40 \\
(2.8 I ; 4.39)\end{array}$ & $\begin{array}{l}4.26 \pm 0.48 \\
(3.30 ; 5.18)\end{array}$ & $\begin{array}{l}2.95 \pm 1.07 \\
(1.07 ; 4.23)\end{array}$ & $\begin{array}{l}5.91 \pm 0.39 \\
(5.44 ; 6.43)\end{array}$ & $\begin{array}{l}5.31 \pm 0.72 \\
(4.23 ; 7.05)\end{array}$ & $\begin{array}{l}4.48 \pm 1.14 \\
(1.07 ; 7.05)\end{array}$ \\
\hline El protein $\left(\mathrm{MJ}^{4}\right)$ & $\begin{array}{l}0.48 \pm 0.06 \\
(0.40 ; 0.62)\end{array}$ & $\begin{array}{l}0.65 \pm 0.07 \\
(0.5 I ; 0.79)\end{array}$ & $\begin{array}{l}0.68 \pm 0.35 \\
(0.12 ; 1.24)\end{array}$ & $\begin{array}{l}0.78 \pm 0.05 \\
(0.7 I ; 0.85)\end{array}$ & $\begin{array}{l}0.80 \pm 0.11 \\
(0.63 ; 1.05)\end{array}$ & $\begin{array}{l}0.69 \pm 0.18 \\
(0.20 ; 1.24)\end{array}$ \\
\hline Satiety iAUC ${ }^{5}$ & $\begin{array}{c}7102.1 \pm 3212.3 \\
(0 ; 11010.0)\end{array}$ & $\begin{array}{c}5262.4 \pm 3171.7 \\
(0 ; 11370.0)\end{array}$ & $\begin{array}{l}6506.3 \pm 1675.3 \\
(2535.0 ; 8535.0)\end{array}$ & $\begin{array}{c}7911.0 \pm 2541.0 \\
(3090.0 ; 11670.0)\end{array}$ & $\begin{array}{r}8698.5 \pm 3092.3^{9} \\
(170.0 ; 15015.0)\end{array}$ & $\begin{array}{c}7097.9 \pm 3237.7^{11} \\
(0 ; 15015.0)\end{array}$ \\
\hline CAS IAOC ${ }^{6}$ & $\begin{array}{c}7057.9 \pm 2538.4 \\
(3037.5 ; 10635.0)\end{array}$ & $\begin{array}{l}5431.2 \pm 2952.5 \\
(511.9 ; 10755.0)\end{array}$ & $\begin{array}{c}6699.9 \pm 2294.4 \\
(2267.9 ; 10338.8)\end{array}$ & $\begin{array}{c}7101.7 \pm 2340.3^{8} \\
(3052.5 ; 11580.0)\end{array}$ & $\begin{array}{l}8439.5 \pm 3074.5^{10} \\
(1372.8 ; 14340.0)\end{array}$ & $\begin{array}{r}6986.9 \pm 3012.3^{12} \\
(511.9 ; 14340.0)\end{array}$ \\
\hline TEF iAUC ${ }^{7}$ & $\begin{array}{r}131.5 \pm 93.1 \\
(1.0 ; 318.0)\end{array}$ & $\begin{array}{c}\mid 68.0 \pm 91.1 \\
(0 ; 482.0)\end{array}$ & $\begin{array}{l}188.4 \pm 128.8 \\
(46.0 ; 402.0)\end{array}$ & $\begin{array}{l}168.2 \pm 124.4 \\
(20.0 ; 398.0)\end{array}$ & $\begin{array}{l}\mid 72.7 \pm 92.2 \\
(20.0 ; 498.0)\end{array}$ & $\begin{array}{r}165.6 \pm 99.1 \\
(0 ; 498.0)\end{array}$ \\
\hline
\end{tabular}

Values are mean $\pm S D$ (min; $\max )$ unless otherwise stated.

'One cup of tea/coffee containing caffeine was served during the measurement of diet-induced thermogenesis.

${ }^{2}$ Spontaneous physical activity during the first $3 \mathrm{~h}$ after the dinner meal in percent per hour.

${ }^{3}$ Energy intake from dinner meal in $\mathrm{MJ}$.

${ }^{4}$ Energy intake from protein in dinner meal in MJ.

${ }^{5}$ The incremental area under the curve for satiety measured by visual analog scales.

${ }^{6}$ Incremental area over the curve for the summary measure Composite Appetite Score. CAS $=($ satiety + fullness + hunger + prospective food intake $) / 4$.

${ }^{7}$ Diet-induced thermogenesis in $\mathrm{kJ} / 3 \mathrm{~h}$ (incremental area under the curve for postprandial energy expenditure).

${ }^{8} n=9$ participants.

${ }^{9} n=36$ participants.

${ }^{10} n=35$ participants.

${ }^{1}{ }^{\prime} n=109$ participants.

${ }^{12} n=107$ participants.

subgroup of the included participants, thus 149 of the 280 participants were not measured in the respiration chambers and data on these participants was excluded. Furthermore, 20 participants were excluded due to missing data on EI, VAS scores, and body mass index (BMI). As a result, 111 healthy participants were included in this IPD meta-analysis. Study characteristics for each of the five included studies are listed in Table 1. Forty-eight of the $111(43 \%)$ included participants were men. The mean $( \pm \mathrm{SD})$ age of all the participants was $32 \pm 9$ years and the mean BMI was $30 \pm 3 \mathrm{~kg} / \mathrm{m}^{2}$.

\section{Design of included studies}

The five included studies were randomized trials testing either different types of meals or medication in the respiration chamber. The participants were standardized with regard to exercise and alcohol intake from $10.00 \mathrm{pm}$ the night before the EE measurements. The dinner meal was served at 18:00-19:15 after 3-6 $\mathrm{h}$ of fasting. The macronutrient compositions of the dinner meals are shown in Table 2. The dinner meal was followed by a postprandial period of $180 \mathrm{~min}$ with appetite and EE measurements (EE measurements from (15) are unpublished). The protocols for the stays in the respiration chamber in the included studies were not substantially different from each other. Physical activity was restricted in the hours prior to the measurements. All participants were sedentary for at least $100 \mathrm{~min}$ prior to and during the 180 -min postprandial EE measurements. The only important difference was the ingestion of caffeine (in the form of one cup of tea or coffee) after the dinner meal during the EE measurement ( $40 \%$ of the included studies) (13-17). The Municipal Ethical Committee of Copenhagen and Frederiksberg, Denmark approved all included studies. 


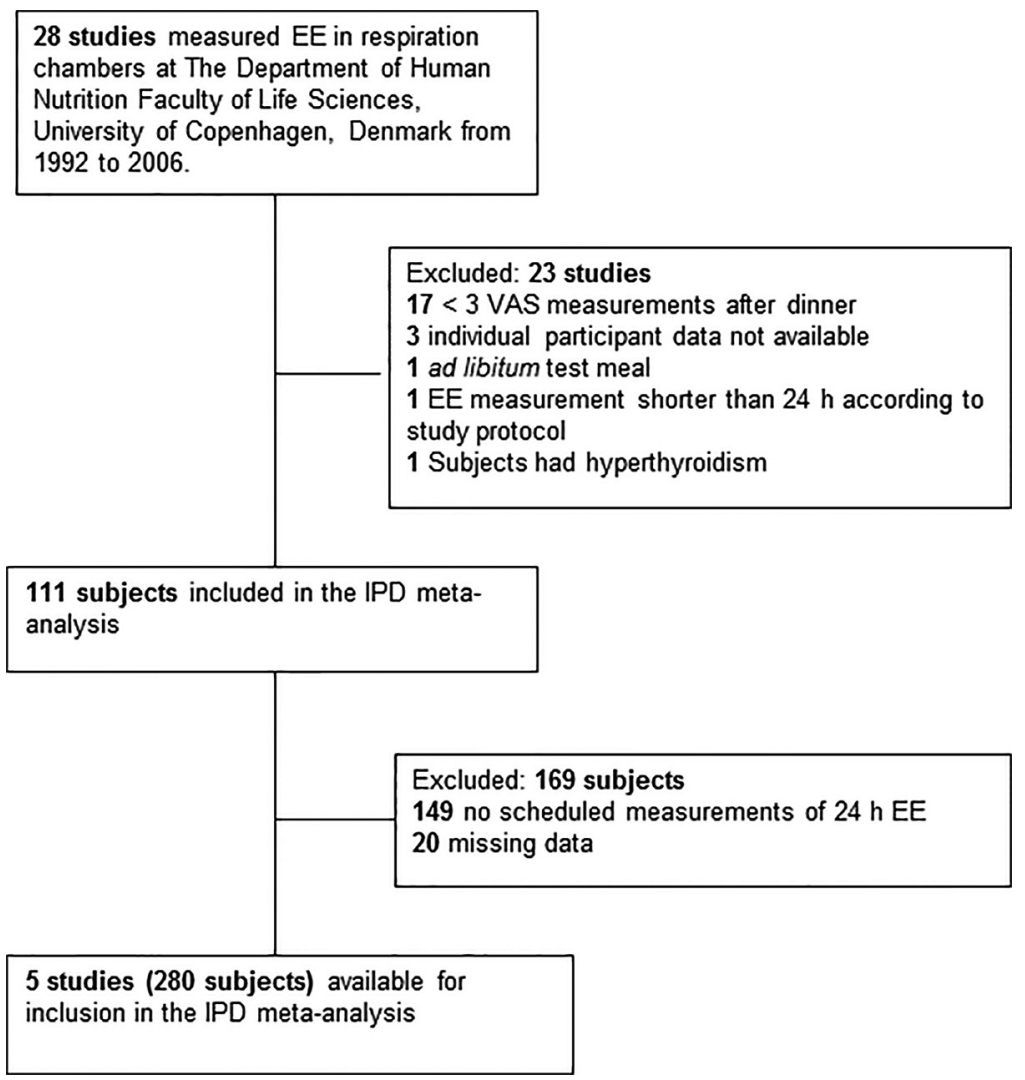

Fig. 1. Flowchart of the selection and inclusion process.

Appetite measures and TEF

Satiety and $\mathrm{TEF}_{\mathrm{iAUC}}$

As illustrated in Fig. 2, the IPD meta-analysis found no overall association between satiety and $\mathrm{TEF}_{\mathrm{iAUC}}$, with the Spearman's $r$-coefficients varying from -0.36 to +0.33 , all being statistically non-significant $(P>0.18)$. Pooling the data from these five individual trials produced a combined Spearman's $r$-coefficient of $0.06(95 \%$ CI: -0.16 to 0.28$)$, providing no support to the hypothesis of an association between satiety and TEF $(P=0.58)$. This result was based on a small amount of heterogeneity, with a negligible degree of inconsistency $\left(I^{2}=15.8 \%\right)$. For sensitivity, we compare this with the more naïve approach - combining all participant data into one correlation analysis (i.e. ignoring the study structure), also resulting in an overall statistically non-significant Spearman's $r$-coefficient $(r=0.079, \quad P=0.42, \quad N=109$ observations). Inclusion of covariates did not affect the association between satiety and $\mathrm{TEF}_{\mathrm{iAUC}}$ (see Supplementary file).

\section{CAS and $\mathrm{TEF}_{\mathrm{iAUC}}$}

There was also no association between CAS and $\mathrm{TEF}_{\mathrm{iAUC}}$ $(P=0.45)$; the pooled Spearman's $r$-coefficient from these five trials was $r=0.08(95 \% \mathrm{CI}$ : -0.12 to 0.28$)$. As presented in Fig. 2, the $r$-values ranged from -0.20 to +0.31 , all being statistically non-significant $(P>0.20)$, and apparently with no inconsistency $\left(I^{2}=0 \%\right)$. For sensitivity, combining all participant data into one correlation analysis also resulted in an overall statistically nonsignificant Spearman's $r$-coefficient $(r=0.051, P=0.60$, $N=107$ observations). Inclusion of covariates did not affect the association between CAS and $\mathrm{TEF}_{\mathrm{iAUC}}$ (see Supplementary file).

\section{Associations between TEF iAUC, satiety, CAS, and El from} protein

Figure 3 illustrates the three different associations with the protein intake in each study; upper part being in relation to $\mathrm{TEF}_{\mathrm{iAUC}}$; middle being in relation to satiety; lower in relation to CAS.

No association between $\mathrm{TEF}_{\mathrm{iAUC}}$ and protein intake was found $(P=0.57)$, with the pooled Spearman's $r$-coefficient being $0.08(95 \% \mathrm{CI}$ : -0.20 to 0.36$)$; with a moderate inconsistency across studies $\left(I^{2}=47.8 \%\right)$. Combining all participant data into one correlation analysis (in analogy to a fixed-effects model) also resulted in an overall statistically non-significant Spearman's $r$-coefficient ( $r=0.08, P=0.39, N=111$ observations). However, we note that one study (15) showed a tendency toward a statistically significant association $(r=0.43$, $P=0.068, N=19$ observations). An association between TEF $_{\text {iAUC }}$ and protein intake was observed $(P=0.009)$ when including the covariates: Sex $(P=0.01)$, caffeine 
Table 2. Macronutrient composition in the dinner meals served in the respiration chambers

\begin{tabular}{|c|c|c|c|c|}
\hline Reference & $n$ & $\begin{array}{c}\text { Carbohydrate } E \\
(\%)\end{array}$ & $\begin{array}{c}\text { Protein E } \\
\text { (\%) }\end{array}$ & $\begin{array}{l}\text { Fat } \mathrm{E} \\
(\%)\end{array}$ \\
\hline Raben et al. (15) & 19 & 50 & 13 & 37 \\
\hline Hansen et al. (13) & 32 & 48 & 15 & 37 \\
\hline \multirow[t]{3}{*}{ Mikkelsen et al. (I7) } & 4 & 42 & 29 & 29 \\
\hline & 4 & 43 & 28 & 29 \\
\hline & 4 & 61 & 11 & 28 \\
\hline Larsen et al. (14) & 10 & 52 & 13 & 35 \\
\hline \multirow[t]{2}{*}{ Rasmussen et al. $(16)^{2}$} & 19 & 45 & 15 & 40 \\
\hline & 19 & 60 & 15 & 25 \\
\hline
\end{tabular}

'Total $n=12$ participants.

${ }^{2}$ Total $n=38$ participants.

intake $(P<0.05)$, and $\mathrm{EI}$ in the dinner meal $(P=0.02)$ (see Supplementary file).

Relating the satiety with protein intake did not indicate any association $(P=0.75)$, as the pooled analysis showed a combined Spearman's $r$-coefficient of $-0.03(95 \% \mathrm{CI}$ : -0.24 to 0.17$)$; with a low degree of inconsistency $\left(I^{2}=\right.$ $5.8 \%$ ). The individual study results ranged from -0.24 to +0.38 with no indication of statistically significant results $(P>0.15)$. Inclusion of covariates did not affect the association between satiety and protein intake (see Supplementary file).

Finally, for CAS in relation to the protein intake, the Spearman's $r$-coefficients varied from -0.30 to +0.34 , all being statistically non-significant $(P>0.18)$. Pooling the data from these five individual trials produced a combined Spearman's $r$-coefficient of $-0.06(95 \%$ CI: -0.26 to 0.14 ), providing no support to the hypothesis of an association between CAS and TEF $(P=0.57)$. Inclusion of covariates did not affect the association between CAS and protein intake (see Supplementary file).

\section{Secondary TEF measures and appetite measures}

Posthoc correlation analysis between $\mathrm{TEF} \%{ }_{\mathrm{EI}}$ and satiety with all participant data combined resulted in an overall non-significant Spearman's $r$-coefficient $(r=0.066, P=$ $0.49, N=109$ observations). Similarly, correlation analysis between $\mathrm{TEF} \%$ and CAS also produced a nonsignificant Spearman's $r$-coefficient $(r=0.054, P=0.58$, $N=107$ observations).

Posthoc correlation analysis between $\mathrm{TEF} \%$ and satiety including participant data from all included studies resulted in a non-significant Spearman's $r$-coefficient ( $r=0.134, P=0.17, N=109$ observations). Finally, similar analysis between $\mathrm{TEF} \%$ and CAS showed a nonsignificant Spearman's $r$-coefficient $(r=0.112, P=0.25$, $N=107$ observations).

\section{Discussion}

We found no association between $\mathrm{TEF}_{\mathrm{iAUC}}$ and the appetite measures, satiety, and CAS. Similarly, no associations were seen between $\mathrm{TEF}^{\mathrm{E}}{ }_{\mathrm{EI}}$ or $\mathrm{TEF} \%$ and the appetite measures.

Previously, four studies examined the association between sensations of appetite and changes in EE following a meal $(6,46-48)$. Westerterp-Plantenga et al. (6) investigated this issue and found significant correlations between the differences (due to different macronutrient compositions in the test-meals) in both satiety and hunger over a 24 -h period, and differences in TEF (expressed as $24-\mathrm{h} \mathrm{TEF}$ in $\mathrm{kJ} /$ day and $\mathrm{TEF} \%{ }_{\mathrm{EI}}$ ). Another study by Westerterp-Plantenga et al. (48) observed a positive correlation between satiety and $\mathrm{TEF} \%_{\mathrm{EI}}$, but no association was found between hunger and $\mathrm{TEF}_{\mathrm{EI}}$. Crovetti et al. (46) found a positive correlation between fullness and TEF (expressed as AUC), but not between satiety and the desire to eat and TEF. Raben et al. (47) documented a positive correlation between satiety and $\mathrm{TEF} \%_{\mathrm{EI}}$, and between fullness and $\mathrm{TEF} \%_{\mathrm{EI}}$. However,

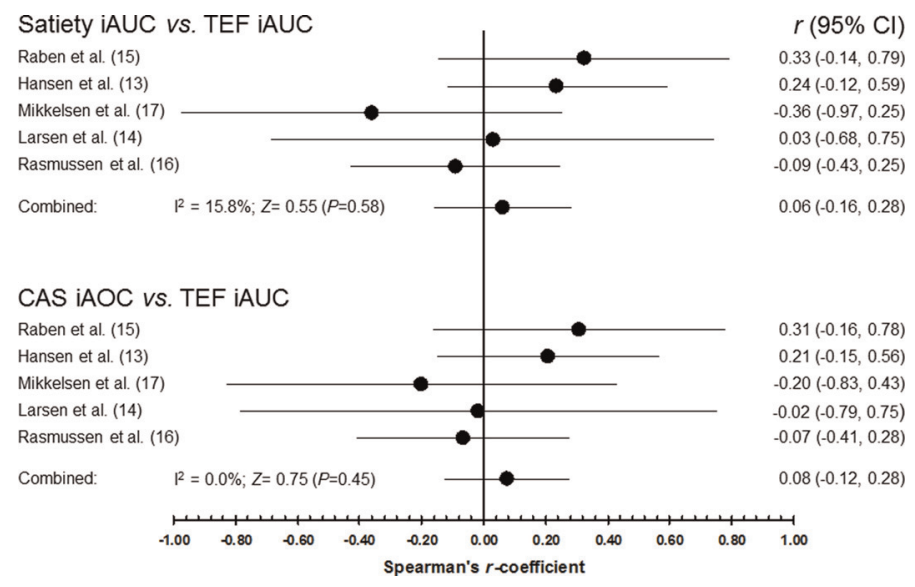

Fig. 2. Forest plot of Spearman's $r$-coefficients. Every dot represents the individual study's $r$-value with $95 \%$ CI indicated by horizontal lines. The overall estimate (pooled random-effects model) from the meta-analysis and its CI are shown at the bottom of each subplot. 


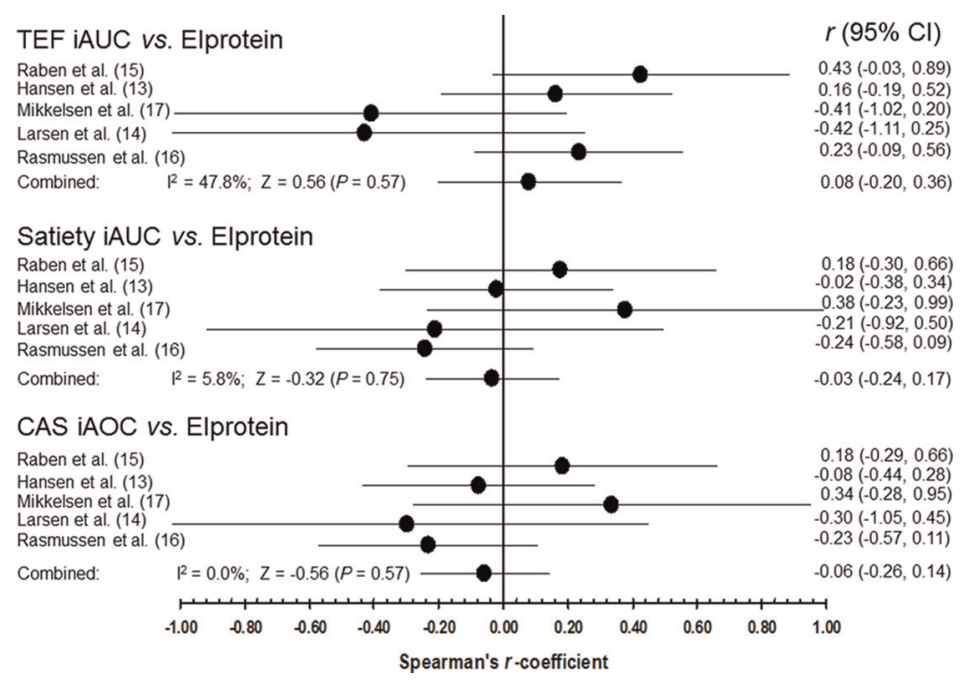

Fig. 3. Forest plot of Spearman's $r$-coefficients. Every dot represents the individual study's $r$-value with $95 \%$ CI indicated by horizontal lines. The overall estimate (pooled random-effects model) from the meta-analysis and its CI are shown at the bottom of each.

no correlation was found between VAS measurements of hunger and prospective food intake (47). Overall, fewer than half of the appetite measures in these studies were correlated with TEF and thus the results are inconclusive.

Our results disclosed no association between TEF and satiety or CAS no matter which calculation method was used for TEF. This could be due to the fact that no association between protein and satiety was found. The lack of association between protein and satiety is supported by Raben et al., who found no difference in satiety when meals similar in energy densities but high in protein (31.8\% of energy), fat, carbohydrate, and alcohol were ingested (49). Nevertheless, a recent review by Veldhorst et al. (7) concluded that the acute satiating effect of protein in single meals is present with a content of $25-81 \%$ of energy from protein. The mean $( \pm S D)$ protein intake in our study was $15.6 \%( \pm 3.8)$ of energy from protein, so this could be too low to trigger a satiating effect. Due to the previously reported effect of protein on EE, we adjusted for the protein content in the statistical analysis $(50,51)$. Only 8 of the 111 participants in the present study received meals containing $>20 \%$ of energy from protein and therefore no subgroup analysis was conducted on groups differing in protein intake. The results of this study may thus only be applicable to participants ingesting meals with normal protein contents ( $\sim 15 \%$ of energy from protein). In other words, the (lack of) associations between satiety and TEF may depend on the amount of protein ingested.

In the primary analyses of TEF and protein, the test for overall effect showed no association $(P=0.57)$. However, including potentially confounding factors in the model resulted in an overall statistically significant Spearman's $r$-coefficient $(P=0.009)$. This association between protein and TEF is supported by existing evidence. The reported
TEF for protein is $20-30 \%$ of energy content compared to fat $(0-3 \%)$ and carbohydrates $(5-10 \%)$ (3). Thus, the higher the protein content of the meal, the larger the effect on $\mathrm{EE}(50,51)$.

The participants in the present study had an average BMI of $30 \mathrm{~kg} / \mathrm{m}^{2}$. One hundred of the 111 included subjects were in weight-stable conditions with study specific mean weight changes of no more than -0.2 $\mathrm{kg} \pm 1.2 \mathrm{~kg}$ to $1.2 \mathrm{~kg} \pm 3.9$ over 28 days to 6 months. Only 11 of the included subjects had a weight loss of no more than $13.1 \pm 0.6 \mathrm{~kg}$ over 8 weeks prior to the measurements in the respiration chambers $(13-17,52)$. Numerous studies have reported a lower TEF in obese participants (53-55). However, other studies have reported no difference in TEF in lean and obese participants (56-58). A posthoc $t$-test analysis comparing the lower and upper quartiles for TEF showed a significant higher body weight in the upper quartile for TEF $(P=$ 0.02 ) but no difference between the quartiles was found for body fat $(P=0.18)$. Whether obesity affects the association between satiety and TEF is also uncertain. This could possibly complicate the comparison of the present study with studies performed on normal-weight participants with a $\mathrm{BMI}<25 \mathrm{~kg} / \mathrm{m}^{2}$.

TEF has been reported to last longer than the 3-h measuring period used in this study and this could be a limitation. However, studies report that the major part of TEF takes place during the first few hours after ingestion of a meal $(59,60)$. Although these studies used meals containing less energy than those in our study, we propose that the 3 -h period in our study still constitutes a valid measure of TEF. One study has suggested a measuring period of $6-\mathrm{h}$ to increase the precision of the TEF measurement, but the highly non-significant results $(P>0.48)$ in the present study makes it unlikely that a 
longer measurement period would alter these findings significantly (59).

TEF was measured in respiration chambers that contain large volumes of air which has to be exchanged continuously to produce valid measures of EE and small differences in TEF may therefore be difficult to detect in respiration chambers (61). This could limit the precision of the short-term (3-h) measurements of EE used in this study. However, based on experience from numerous respiration chamber studies at our department, we know that the chambers have a short response time: about $15 \mathrm{~min}$ for measuring larger differences in EE (bicycling) and about $60 \mathrm{~min}$ for detecting smaller differences in EE. Furthermore, the participants are not stressed in the chambers, in contrast to hood and mask measurement systems that may in particular affect their measured $\mathrm{R}$-value. We therefore consider the respiration chambers to be a reliable and useful method for the purposes of this IPD meta-analysis.

All five included studies were conducted at our department and the respiration chambers and the study protocols were relatively similar, which implies a small variation between the studies. Furthermore, all protocols stated that the participants were sedentary during the 180-min postprandial EE measurement, meaning that physical activity during the TEF measuring period did not influence the results. However, this means that the results of these studies may all be affected by the same methodological issues. Similarly, it also increases the risk of our inclusion criteria being biased (62). Nevertheless, the present IPD meta-analysis is the first collection of a large sample of data on appetite and TEF in participants ingesting a meal containing approximately $15 \%$ of energy from protein.

If, in contrast to what our meta-analysis suggests, there actually exists an association between satiety and TEF, the question is whether this association is causal, or just the result of a protein induced concomitant elevation in both satiety and TEF, that is, temporal co-variation. The associations between protein and satiety $(7,46,63,64)$ and between protein and TEF (63-65), respectively, are both well documented. Furthermore, the higher the protein content, the higher both satiety and TEF will be. Nevertheless, the association between satiety and $\mathrm{TEF}$, or the mechanisms potentially responsible for this possible association, is currently not well documented. Westerterp-Plantenga et al. (6) suggest that the increased oxygen consumption (and body temperature) associated with TEF may result in decreased oxygen availability, which may then induce satiety through unknown mechanisms. The authors based this suggestion on studies showing that high altitude, exercise, and chronic obstructive pulmonary disease, which are all characterized by limited oxygen availability, are all associated with higher satiety scores. However, in our study it is an unlikely explanation since the magnitude of TEF rarely reaches levels of oxygen shortage. The design of the present study does not allow for the investigation of causal associations and therefore, this requires further research in the future. Future studies should also consider the ranges of protein intake, the length of the EE measurement session, the number and frequency of appetite measures, and possible measurements of satietyrelated hormones.

\section{Conclusion}

In conclusion, the IPD meta-analysis found no association between satiety or CAS and TEF at protein intakes $\sim 15 \mathrm{E} \%$ of the meal (range 11-30 E\%). The calculation method for TEF did not influence these findings. However, even though our study did not show any associations, this does not rule out the possibility that associations may be present at higher protein intakes.

\section{Acknowledgements}

The authors thank Charlotte Kostecki and John G. Lind for their assistance. The authors' responsibilities were as follows: A.-M. R., N. T. G. and L. G. R. collected and prepared the data for analyses. R. C. conducted all the statistical analyses. A.-M. R. and N. T. G. wrote the manuscript. All authors helped in interpreting the data and reviewing the article.

\section{Conflict of interest and funding}

The authors have no conflict of interest to report. This research was supported by the OPUS project "Optimal well-being, development and health for Danish children through a healthy New Nordic Diet" (OPUS is funded by a grant from the Nordea Foundation) and by EC FP6 Diabesity project (LSHM-CT-2003-503041). The "Oak Foundation" is thanked for providing economic support to The Parker Institute.

\section{References}

1. Blundell J. Pharmacological approaches to appetite suppression. Trends Pharmacol Sci 1991; 12: 147-57.

2. Blundell JE, Lawton CL, Cotton JR, Macdiarmid JI. Control of human appetite: implications for the intake of dietary fat. Annu Rev Nutr 1996; 16: 285-319.

3. Tappy L. Thermic effect of food and sympathetic nervous system activity in humans. Reprod Nutr Dev 1996; 36: 391-7.

4. Westerterp KR. Diet induced thermogenesis. Nutr Metab (Lond) 2004; 1: 5 .

5. Strominger JL, Brobeck JR. A mechanism of regulation of food intake. Yale J Biol Med 1953; 25: 383-90.

6. Westerterp-Plantenga MS, Rolland V, Wilson SA, Westerterp KR. Satiety related to $24 \mathrm{~h}$ diet-induced thermogenesis during high protein/carbohydrate vs. high fat diets measured in a respiration chamber. Eur J Clin Nutr 1999; 53: 495-502.

7. Veldhorst M, Smeets A, Soenen S, Hochstenbach-Waelen A, Hursel R, Diepvens K, et al. Protein-induced satiety: effects and mechanisms of different proteins. Physiol Behav 2008; 94: 300-7. 
8. Westerterp-Plantenga MS, Westerterp KR, Rubbens M, Verwegen CR, Richelet JP, Gardette B. Appetite at "high altitude" [Operation Everest III (Comex- '97)]: a simulated ascent of Mount Everest. J Appl Physiol 1999; 87: 391-9.

9. van Baak MA. Meal-induced activation of the sympathetic nervous system and its cardiovascular and thermogenic effects in man. Physiol Behav 2008; 94: 178-86.

10. Astrup A, Thorbek G, Lind J, Isaksson B. Prediction of 24-h energy expenditure and its components from physical characteristics and body composition in normal-weight humans. Am J Clin Nutr 1990; 52: 777-83.

11. Flint A, Raben A, Blundell JE, Astrup A. Reproducibility, power and validity of visual analogue scales in assessment of appetite sensations in single test meal studies. Int $\mathbf{J}$ Obes Relat Metab Disord 2000; 24: 38-48.

12. Anderson GH, Catherine NL, Woodend DM, Wolever TM. Inverse association between the effect of carbohydrates on blood glucose and subsequent short-term food intake in young men. Am J Clin Nutr 2002; 76: 1023-30.

13. Hansen DL, Toubro S, Stock MJ, Macdonald IA, Astrup A. The effect of sibutramine on energy expenditure and appetite during chronic treatment without dietary restriction. Int J Obes Relat Metab Disord 1999; 23: 1016-24.

14. Larsen TM, Toubro S, van Baak MA, Gottesdiener KM, Larson P, Saris WH, et al. Effect of a 28-d treatment with L-796568, a novel beta(3)-adrenergic receptor agonist, on energy expenditure and body composition in obese men. Am J Clin Nutr 2002; 76: 780-8.

15. Raben A, Vasilaras TH, Moller AC, Astrup A. Sucrose compared with artificial sweeteners: different effects on ad libitum food intake and body weight after $10 \mathrm{wk}$ of supplementation in overweight subjects. Am J Clin Nutr 2002; 76: $721-9$.

16. Rasmussen LG, Larsen TM, Mortensen PK, Due A, Astrup A. Effect on 24-h energy expenditure of a moderate-fat diet high in monounsaturated fatty acids compared with that of a low-fat, carbohydrate-rich diet: a 6-mo controlled dietary intervention trial. Am J Clin Nutr 2007; 85: 1014-22.

17. Mikkelsen PB, Toubro S, Astrup A. Effect of fat-reduced diets on 24-h energy expenditure: comparisons between animal protein, vegetable protein, and carbohydrate. Am J Clin Nutr 2000; 72: 1135-41.

18. Thompson S, Ekelund U, Jebb S, Lindroos AK, Mander A, Sharp S, et al. A proposed method of bias adjustment for metaanalyses of published observational studies. Int $\mathrm{J}$ Epidemiol 2011; 40: 765-77.

19. Cochran W. The combination of estimates from different experiments. Biometrics 1954; 10: 101-29.

20. DerSimonian R, Laird N. Meta-analysis in clinical trials. Control Clin Trials 1986; 7: 177-88.

21. Higgins JP, Thompson SG. Quantifying heterogeneity in a metaanalysis. Stat Med 2002; 21: 1539-58.

22. Higgins JP, Thompson SG, Deeks JJ, Altman DG. Measuring inconsistency in meta-analyses. BMJ 2003; 327: 557-60.

23. Simmonds MC, Higgins JP. Covariate heterogeneity in metaanalysis: criteria for deciding between meta-regression and individual patient data. Stat Med 2007; 26: 2982-99.

24. Marklund M, Christensen R, Torp-Pedersen S, Thomsen C, Nolsoe CP. Signal intensity of normal breast tissue at MR mammography on midfield: applying a random coefficient model evaluating the effect of doubling the contrast dose. Eur J Radiol 2007; 69: 93-101.

25. Higgins JP, Whitehead A, Turner RM, Omar RZ, Thompson SG. Meta-analysis of continuous outcome data from individual patients. Stat Med 2001; 20: 2219-41.
26. Astrup A, Buemann B, Christensen NJ, Madsen J, Gluud C, Bennett $\mathrm{P}$, et al. The contribution of body composition, substrates, and hormones to the variability in energy expenditure and substrate utilization in premenopausal women. J Clin Endocrinol Metab 1992; 74: 279-86.

27. Astrup A, Buemann B, Christensen NJ, Toubro S. Failure to increase lipid oxidation in response to increasing dietary fat content in formerly obese women. Am J Physiol 1994; 266: E592-9.

28. Belza A, Jessen AB. Bioactive food stimulants of sympathetic activity: effect on 24-h energy expenditure and fat oxidation. Eur J Clin Nutr 2005; 59: 733-41.

29. Bosselaers I, Buemann B, Victor OJ, Astrup A. Twenty-fourhour energy expenditure and substrate utilization in body builders. Am J Clin Nutr 1994; 59: 10-2.

30. Buemann B, Astrup A, Madsen J, Christensen NJ. A 24-h energy expenditure study on reduced-obese and nonobese women: effect of beta-blockade. Am J Clin Nutr 1992; 56: 662-70.

31. Buemann B, Astrup A, Christensen NJ, Madsen J. Effect of moderate cold exposure on 24-h energy expenditure: similar response in postobese and nonobese women. Am J Physiol 1992; 263: E1040-5.

32. Buemann B, Toubro S, Astrup A. Substrate oxidation and thyroid hormone response to the introduction of a high fat diet in formerly obese women. Int J Obes Relat Metab Disord 1998; 22: 869-77.

33. Buemann B, Toubro S, Astrup A. D-Tagatose, a stereoisomer of d-fructose, increases hydrogen production in humans without affecting 24-hour energy expenditure or respiratory exchange ratio. J Nutr 1998; 128: 1481-6.

34. Buemann B, Toubro S, Astrup A. Effects of the two beta3agonists, ZD7114 and ZD2079 on 24 hour energy expenditure and respiratory quotient in obese subjects. Int $\mathrm{J}$ Obes Relat Metab Disord 2000; 24: 1553-60.

35. Hansen M, Morthorst R, Larsson B, Flyvbjerg A, Rasmussen $\mathrm{MH}$, Orskov $\mathrm{H}$, et al. Effects of 2 wk of $\mathrm{GH}$ administration on 24-h indirect calorimetry in young, healthy, lean men. Am J Physiol Endocrinol Metab 2005; 289: E1030-8.

36. Harder H, Nielsen L, Tu DT, Astrup A. The effect of liraglutide, a long-acting glucagon-like peptide 1 derivative, on glycemic control, body composition, and 24-h energy expenditure in patients with type 2 diabetes. Diabetes Care 2004; 27: 1915-21.

37. Jacobsen R, Lorenzen JK, Toubro S, Krog-Mikkelsen I, Astrup A. Effect of short-term high dietary calcium intake on 24-h energy expenditure, fat oxidation, and fecal fat excretion. Int $\mathbf{J}$ Obes (Lond) 2005; 29: 292-301.

38. Raben A, Macdonald I, Astrup A. Replacement of dietary fat by sucrose or starch: effects on $14 \mathrm{~d}$ ad libitum energy intake, energy expenditure and body weight in formerly obese and never-obese subjects. Int J Obes Relat Metab Disord 1997; 21: 846-59.

39. Toubro S, Christensen NJ, Astrup A. Reproducibility of 24-h energy expenditure, substrate utilization and spontaneous physical activity in obesity measured in a respiration chamber. Int J Obes Relat Metab Disord 1995; 19: 544-9.

40. Toubro S, Sorensen TI, Hindsberger C, Christensen NJ, Astrup A. Twenty-four-hour respiratory quotient: the role of diet and familial resemblance. J Clin Endocrinol Metab 1998; 83: 275864.

41. Verdich C, Toubro S, Buemann B, Holst JJ, Bulow J, Simonsen $\mathrm{L}$, et al. Leptin levels are associated with fat oxidation and dietary-induced weight loss in obesity. Obes Res 2001; 9: 452-61.

42. Klausen B, Toubro S, Ranneries C, Rehfeld JF, Holst JJ, Christensen NJ, et al. Increased intensity of a single exercise 
bout stimulates subsequent fat intake. Int $\mathbf{J}$ Obes Relat Metab Disord 1999; 23: 1282-7.

43. Gregersen NT, Bitz C, Krog-Mikkelsen I, Hels O, Kovacs E, Mela D, et al. Minor effects of green tea catechins and caffeine on energy metabolism in normal weight males. Int J Obes 2007; 31: S167.

44. Mersebach H, Svendsen OL, Astrup A, Feldt-Rasmussen U. Abnormal sympathoadrenal activity, but normal energy expenditure in hypopituitarism. J Clin Endocrinol Metab 2003; 88: 5689-95.

45. Vasilaras TH, Raben A, Astrup A. Twenty-four hour energy expenditure and substrate oxidation before and after 6 months' ad libitum intake of a diet rich in simple or complex carbohydrates or a habitual diet. Int J Obes Relat Metab Disord 2001; 25: 954-65.

46. Crovetti R, Porrini M, Santangelo A, Testolin G. The influence of thermic effect of food on satiety. Eur J Clin Nutr 1998; 52: 482-8.

47. Raben A, Christensen NJ, Madsen J, Holst JJ, Astrup A. Decreased postprandial thermogenesis and fat oxidation but increased fullness after a high-fiber meal compared with a lowfiber meal. Am J Clin Nutr 1994; 59: 1386-94.

48. Westerterp-Plantenga MS, Wijckmans-Duijsens NE, Verboeketvan de Venne WP, De GK, Weststrate JA, et al. Diet-induced thermogenesis and satiety in humans after full-fat and reducedfat meals. Physiol Behav 1997; 61: 343-9.

49. Raben A, Agerholm-Larsen L, Flint A, Holst JJ, Astrup A. Meals with similar energy densities but rich in protein, fat, carbohydrate, or alcohol have different effects on energy expenditure and substrate metabolism but not on appetite and energy intake. Am J Clin Nutr 2003; 77: 91-100.

50. Johnston CS, Day CS, Swan PD. Postprandial thermogenesis is increased $100 \%$ on a high-protein, low-fat diet versus a highcarbohydrate, low-fat diet in healthy, young women. J Am Coll Nutr 2002; 21: 55-61.

51. Luscombe ND, Clifton PM, Noakes M, Parker B, Wittert G. Effects of energy-restricted diets containing increased protein on weight loss, resting energy expenditure, and the thermic effect of feeding in type 2 diabetes. Diabetes Care 2002; 25: 652-7.

52. Due A, Larsen TM, Mu H, Hermansen K, Stender S, Astrup A. Comparison of 3 ad libitum diets for weight-loss maintenance, risk of cardiovascular disease, and diabetes: a 6-mo randomized, controlled trial. Am J Clin Nutr 2008; 88: 1232-41.

53. Astrup A, Andersen T, Christensen NJ, Bulow J, Madsen J, Breum L, et al. Impaired glucose-induced thermogenesis and arterial norepinephrine response persist after weight reduction in obese humans. Am J Clin Nutr 1990; 51: 331-7.

54. Blaak EE, Hul G, Verdich C, Stich V, Martinez JA, Petersen M, et al. Impaired fat-induced thermogenesis in obese subjects: the NUGENOB study. Obesity 2007; 15: 653-63.
55. Marrades MP, Martinez JA, Moreno-Aliaga MJ. Differences in short-term metabolic responses to a lipid load in lean (resistant) vs obese (susceptible) young male subjects with habitual high-fat consumption. Eur J Clin Nutr 2007; 61: 166-74.

56. Maffeis C, Schutz Y, Grezzani A, Provera S, Piacentini G, Tato L. Meal-induced thermogenesis and obesity: is a fat meal a risk factor for fat gain in children? J Clin Endocrinol Metab 2001; 86: 214-9.

57. Marques-Lopes I, Forga L, Martinez JA. Thermogenesis induced by a high-carbohydrate meal in fasted lean and overweight young men: insulin, body fat, and sympathetic nervous system involvement. Nutrition 2003; 19: 25-9.

58. Tentolouris N, Pavlatos S, Kokkinos A, Perrea D, Pagoni S, Katsilambros N. Diet-induced thermogenesis and substrate oxidation are not different between lean and obese women after two different isocaloric meals, one rich in protein and one rich in fat. Metabolism 2008; 57: 313-20.

59. Reed GW, Hill JO. Measuring the thermic effect of food. Am J Clin Nutr 1996; 63: 164-9.

60. Weststrate JA. Resting metabolic rate and diet-induced thermogenesis: a methodological reappraisal. Am J Clin Nutr 1993; 58: 592-601.

61. Murgatroyd PR, Shetty PS, Prentice AM. Techniques for the measurement of human energy expenditure: a practical guide. Int J Obes Relat Metab Disord 1993; 17: 549-68.

62. Egger M, Smith GD. Bias in location and selection of studies. BMJ 1998; 316: 61-6.

63. Halton TL, Hu FB. The effects of high protein diets on thermogenesis, satiety and weight loss: a critical review. J Am Coll Nutr 2004; 23: 373-85.

64. Paddon-Jones D, Westman E, Mattes RD, Wolfe RR, Astrup A, Westerterp-Plantenga M. Protein, weight management, and satiety. Am J Clin Nutr 2008; 87: 1558S-61S.

65. Lejeune MP, Westerterp KR, Adam TC, Luscombe-Marsh ND, Westerterp-Plantenga MS. Ghrelin and glucagon-like peptide 1 concentrations, 24-h satiety, and energy and substrate metabolism during a high-protein diet and measured in a respiration chamber. Am J Clin Nutr 2006; 83: 89-94.

\footnotetext{
*Anne-Marie Ravn

Faculty of Science

Department of Nutrition, Exercise and Sports

University of Copenhagen

Rolighedsvej 26

DK-1958 Frederiksberg C, Denmark

Tel: +4535332187

Fax: +4535332483

Email: rav@life.ku.dk
} 